\title{
Inuit suicide prevention strategy strives to save lives
}

I

$\mathrm{n}$ an isolated community in Northern Quebec, a place shaken by five suicides and 85 attempts by Inuit youth in the last eight months, a national Inuit political organization released a suicide prevention strategy that its leaders hope will finally begin to arrest the highest rates of suicide in Canada.

"The National Inuit Suicide Prevention Strategy is premised on the belief that suicide among Inuit is a preventable public health crisis that demands a systematic response from all who wish to work with Inuit," said Natan Obed, president of Inuit Tapiriit Kanatami (ITK). "If we truly value Inuit life, then we will take the actions necessary to address the root causes of suicide."

Obed, federal Health Minister Dr. Jane Philpott, and provincial, territorial and regional Inuit leaders released the strategy in an emotional gathering July 27 in Kuujjuaq. It is the culmination of over two years' work by ITK and other Inuit organizations, with support from the Mental Health Commission of Canada and the Centre for Addiction and Mental Health. The strategy outlines reasons behind the suicide risks Inuit face, and offers a plan to reduce risk factors and strengthen protective measures.

The federal government pledged $\$ 9$ million over three years to help implement the strategy, while acknowledging it will likely take time and more resources to reduce the elevated rates of suicide across all four regions of Inuit Nunangat: Nunavik, Nunatsiavut, in northern Labrador, Nunavut and Inuvialuit, in the Northwest Territories.

"Every one of us, including myself, thinks about loved ones that have contemplated, attempted or died by suicide," said Philpott, her voice breaking. "But the way out involves acknowledging that traumatic history, as we are doing today. There are lessons in our painful past."

From 1999 to 2013, there were 745 Inuit deaths by suicide in the four regions. That number now exceeds 800 . The rate of suicide in Nunavik and Nunavut is 10 times Canada's national average of 11 per 100 000. In Nunatsiavut, the rate from 2009-2013 was 275 deaths per $100000-25$ times the national suicide rate.

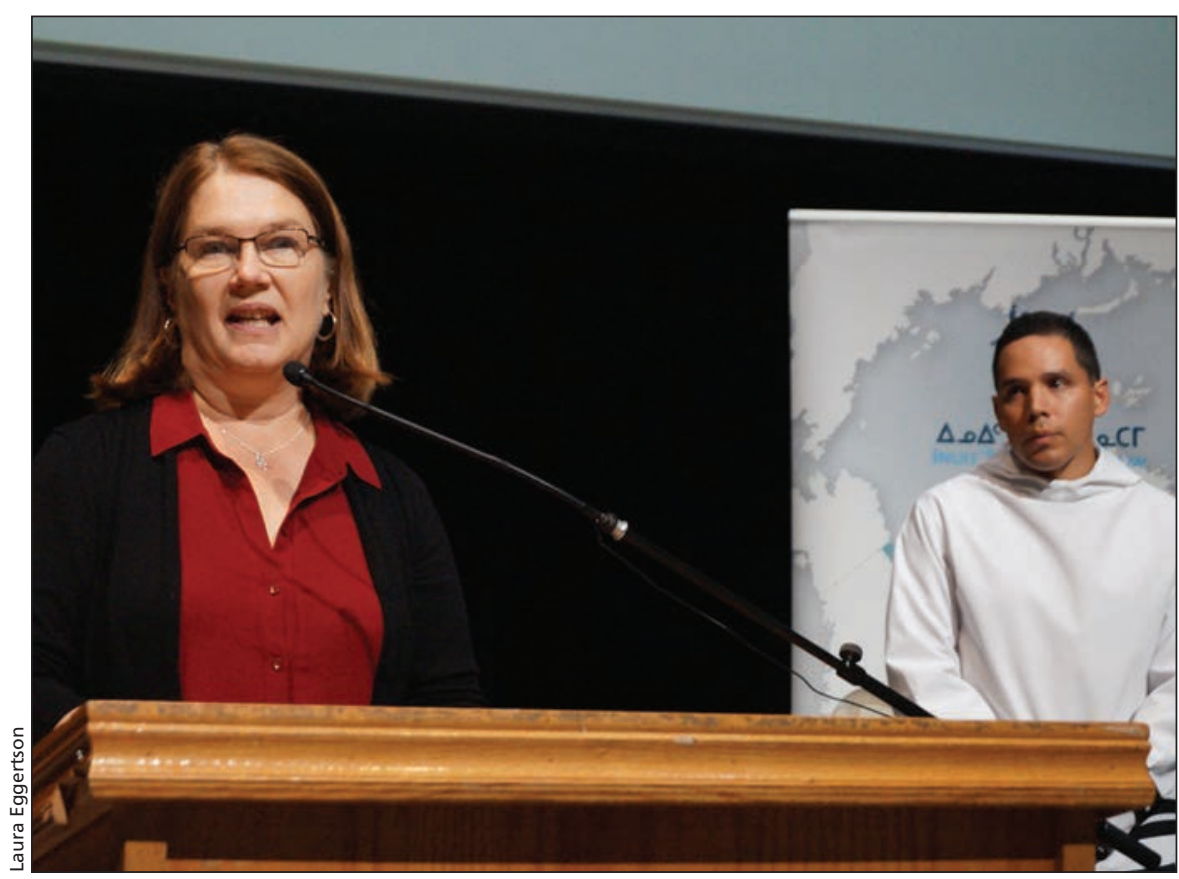

Federal Health Minister Dr. Jane Philpott (left) announced \$9 million for a National Inuit Suicide Prevention Strategy, which was released by Inuit Tapiriit Kanatami President Natan Obed and others on July 27. 


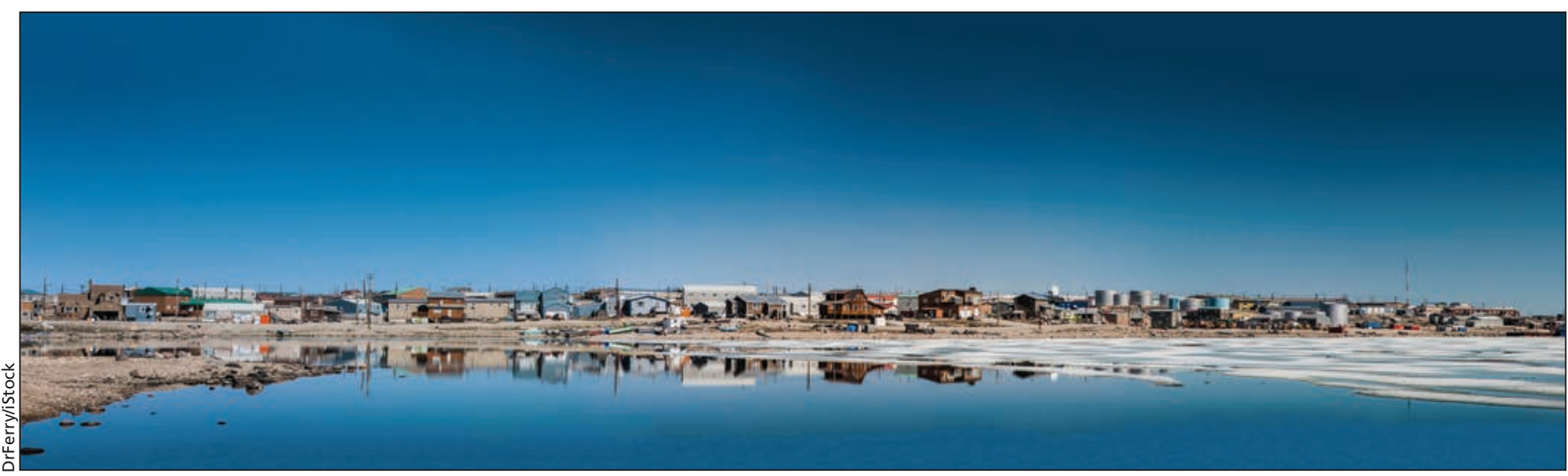

The rate of suicide in Nunavut is $\mathbf{1 0}$ times Canada's national average.

The strategy identifies critical risk factors for Inuit, including:

- the historical trauma of forced relocations, residential schools, slaughter of dog teams and colonialism;

- early adversity, including physical and sexual abuse;

- social inequity, including food insecurity, inadequate housing, poverty and lack of services;

- the intergenerational trauma of families wounded by violence and suicide;

- mental illness and substance abuse; and,

- the acute stress of loss, hopelessness and isolation.

These factors drive the public health crisis, which is disproportionately affecting those under 30 years old, including children as young as 11 who have ended their lives. forcibly resettled in 1959. Obed chose the location to draw attention to the severity of the suicide crisis there - but also because his great-uncle, Joshua Obed, was among the community leaders forced to move his people from Hebron into largely white settlements.

"My heart is in Hebron today, and any Inuit community or traditional homeland where Inuit were relocated or forced out of their homes," said Obed.

"I think of all the things that have gone on in the families of those people who were relocated," he added, choking back tears. "In many ways, myself, my children, are still looking for a place that meant as much to us as Hebron meant to Joshua and his family."

The strategy will focus ITK activities on communication, knowledgesharing, research, education and advo-

\section{If we truly value Inuit life, then we will take the actions necessary to address the root causes of suicide}

The strategy concentrates on strengthening protective factors that reduce suicide risk. These include increasing cultural continuity, social equity and family strength, and encouraging the healthy development of children. It also aims to improve mental wellness, through access to Inuit-specific mental health services and social supports, and resources for regulating and coping with acute stress.

Due to bad weather, ITK changed its plan to release the strategy in Hebron, Nunatsiavut, the site of an abandoned Inuit community whose residents were cacy. Each region will develop its own prevention strategy, elements of which will include ensuring health, education, social services and policing are traumainformed and culturally safe. Protecting children from abuse and developing child-welfare placements that promote cultural connection and community will be stressed. The strategy also calls for a network of helplines, sharing of best suicide prevention practices and train-the-trainer programs in suicide prevention. Inuit suicide and attempt data will be tracked.

The strategy highlights federal, provincial and territorial actions to improve social equity and social determinants of health, as well as increase access to Inuit-specific addiction treatment, mental health and wellness services within communities. Strategies to help children include new parenting resources to reduce the transmission of intergenerational trauma, identifying at-risk children in schools, and promoting resilience through early childhood development programs.

"Focusing our resources and efforts on supporting families and nurturing healthy Inuit children is the most impactful way to ensure that people never reach the point where they consider suicide," the strategy states.

In these sparsely populated territories and regions — there are only 60000 people in all of Inuit Nunangat - no one remains untouched by suicide. Most people have lost a family member or close friend, some more than one. For Sean Lyall, Minister of Culture, Recreation and Tourism for Nunatsiavut, the launch of the prevention strategy provides hope after decades of loss. His best friend in Nain, Labrador, completed suicide more than 20 years ago, when they were both 18 .

"This is an emotional day, but it's about celebrating life," Lyall says. "It's about the future." - Laura Eggertson, Kuujjuaq, Que.

CMAJ 2016. DOI:10.1503/cmaj.109-5309

\section{More News online}

To read more CMAJ news articles, visit cmaj.ca/site/home/news.xhtml 